\title{
Epidemiology, prevention and management of early postpartum hemorrhage - a systematic review
}

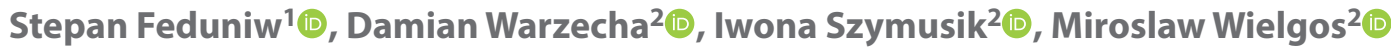 \\ 'Students Scientific Association at the 1st Department of Obstetrics and Gynecology, Medical University of Warsaw, Poland \\ ${ }_{2}^{2} 7^{\text {st }}$ Department of Obstetrics and Gynecology, Medical University of Warsaw, Poland
}

\begin{abstract}
Early Postpartum Hemorrhage (EPH) is one of the leading causes of postpartum mortality. It is defined as blood loss of at least $500 \mathrm{~mL}$ after vaginal or $1000 \mathrm{~mL}$ following cesarean delivery within 24 hours postpartum. The following paper includes literature review aimed to estimate the incidence and predictors of early postpartum hemorrhage (EPH). Available prevention and treatment methods were also assessed. The inclusion criteria for the study were met by 52 studies.

The exact frequency of EPH in different populations varies from $1.2 \%$ to $12.5 \%$. Maternal, pregnancy-associated, laborcorrelated and sociodemographic risk factors seem to be important predictors of EPH. In these cases appropriate prophylaxis should be considered. However, EPH may occur without previous risk factors. The main reason for EPH is uterine atony which contributes to up to $80 \%$ of cases of postpartum hemorrhage (PPH). Other common reasons for PPH include genital tract injuries, placenta accreta or coagulopathies. Interestingly, the majority of uterotonics seem to have a similar effect. However, carbetocin seems to be the most effective in certain situations.

Appropriate diagnosis of EPH is the most important issue. The treatment should be causative. The first-line treatment should include uterotonics. Surgical interventions, if required, should be performed without delay, although preoperative uterine tamponade should be considered due to its high effectiveness.

Medical staff training in medical simulation centers is an important factor that improves the outcomes of EPH treatment. It provides adaptation to hospital protocols, team work improvement, self-confidence building, more accurate blood loss evaluation and reduced perception of stress. The implementation of systematic trainings provides better outcomes in the future. Key words: postpartum hemorrhage; delivery; perinatology; medical simulation
\end{abstract}

Ginekologia Polska 2020; 91, 1: 38-44

\section{INTRODUCTION}

Early postpartum hemorrhage (EPH) is usually defined as blood loss of at least $500 \mathrm{~mL}$ following vaginal delivery (VD) or $1000 \mathrm{~mL}$ following a cesarean section (CS) within 24 hours postpartum [1-3]. Late postpartum hemorrhage (LPH) occurs after 24 hours following labor and complicates $0.23 \%$ of deliveries. According to the American College of Obstetricians and Gynecologists, EPH may be recognized with the presence of signs of hypovolemia within 24 hours after delivery [4]. EPH may be divided into minor (500-1000 mL), moderate (1001-2000 mL) and severe (> $2000 \mathrm{~mL}$ ) [3]. This complication significantly impacts global women's health as the most frequent reason for perinatal deaths all over the world [2].

The volume of blood loss is usually estimated visually. However, this method is connected with a high possibility of error. The underestimation occurs in 30 to $50 \%$ if it is only visual [1]. To make the assessment more objective it is highly advisable to count utilized medical materials, such as surgical towels and drapes. Estimating weight difference of dry unused materials and those soaked with blood seems to be another effective method. Using a calibrated collector bag is also recommended for a more accurate blood loss estimation. Gravimetric blood loss measurement includes weighing bags after delivery [5]. Modified Brecher's formula consists in hemoglobin measurement after delivery which makes the evaluation more accurate.

Undiagnosed abnormal postpartum blood loss (UP$\mathrm{PBL}$ ) is defined as decrease in hemoglobin level of at least $2 \mathrm{~g} / \mathrm{dL}$ without any symptoms or signs of EPH [6]. Apart from an increased risk of maternal mortality (12 to $17.2 \%$ ) EPH may lead to further serious complications related to severe 
anemia, such as acute kidney injury (29.3\%), hepatic failure, Sheehan Syndrome, adult respiratory distress syndrome (24.6\%) and disseminated intravascular coagulopathy (DIC) (11.7\%) [2].

The following paper includes a literature review of recent studies regarding $\mathrm{PPH}$. The main aim of the study was to estimate the incidence and predictors of EPH. Available prevention and treatment methods of EPH were also assessed.

\section{MATERIAL AND METHODS}

The authors searched PubMed database for articles concerning postpartum hemorrhage published from June 2014 to April 2019. Searching with'postpartum hemorrhage' query revealed 186 original studies. The inclusion criteria for the study were: a uniform definition of EPH (blood loss of at least $500 \mathrm{~mL}$ after VD or $1000 \mathrm{~mL}$ following CS within 24 hours postpartum), a study group $\geq 250$ patients and the English language of the manuscripts. 52 studies met the inclusion criteria (Fig. 1).

\section{RESULTS}

According to the WHO postpartum hemorrhage is one of the leading reasons for postpartum mortality, especially in developing countries of Asia (30.8\%) and Africa (33.9\%). Conversely, in developed countries the average mortality rate was estimated to $13.4 \%$ of all PPHs (1.2-49.6\%). The exact frequency of EPH in different populations is shown in Table 1 [6-10] and varies from $0.4 \%$ to $33 \%$.

\section{Etiology}

The leading cause of EPH is uterine atony which contributes 60 to $80 \%$ of those complications and $20-30 \%$ of mothers' deaths [10]. Childbirth via CS may also lead to PPH. There are only few papers concerning PPH occurrence after CS in which $\mathrm{PPH}$ ratio amounted to $0.3-6 \%$ [11]. The prevalence of PPH has increased over the past few years, which may be caused by an increased incidence of uterine atony and CS. The number of emergency hysterectomies (5.8-6.3/10,000 births), blood transfusions, performing B-Lynch sutures (10.7/10,000 births) and uterine artery embolizations are the most correlated with uterine atony. Other common causes of EPH are genital tract injuries or episiotomy (16.7\%), placental abnormalities (4 to $36 \%$ of retained placenta, abnormal placental implantation or placental abruption) or coagulopathies (e.g. anticoagulant treatment or DIC) (7.4\%) [10].

\section{Risk factors}

Unmodifiable risk factors of EPH include a history of EPH $(O R=2.3-10.5)$ and a delivery of a large for gestational age

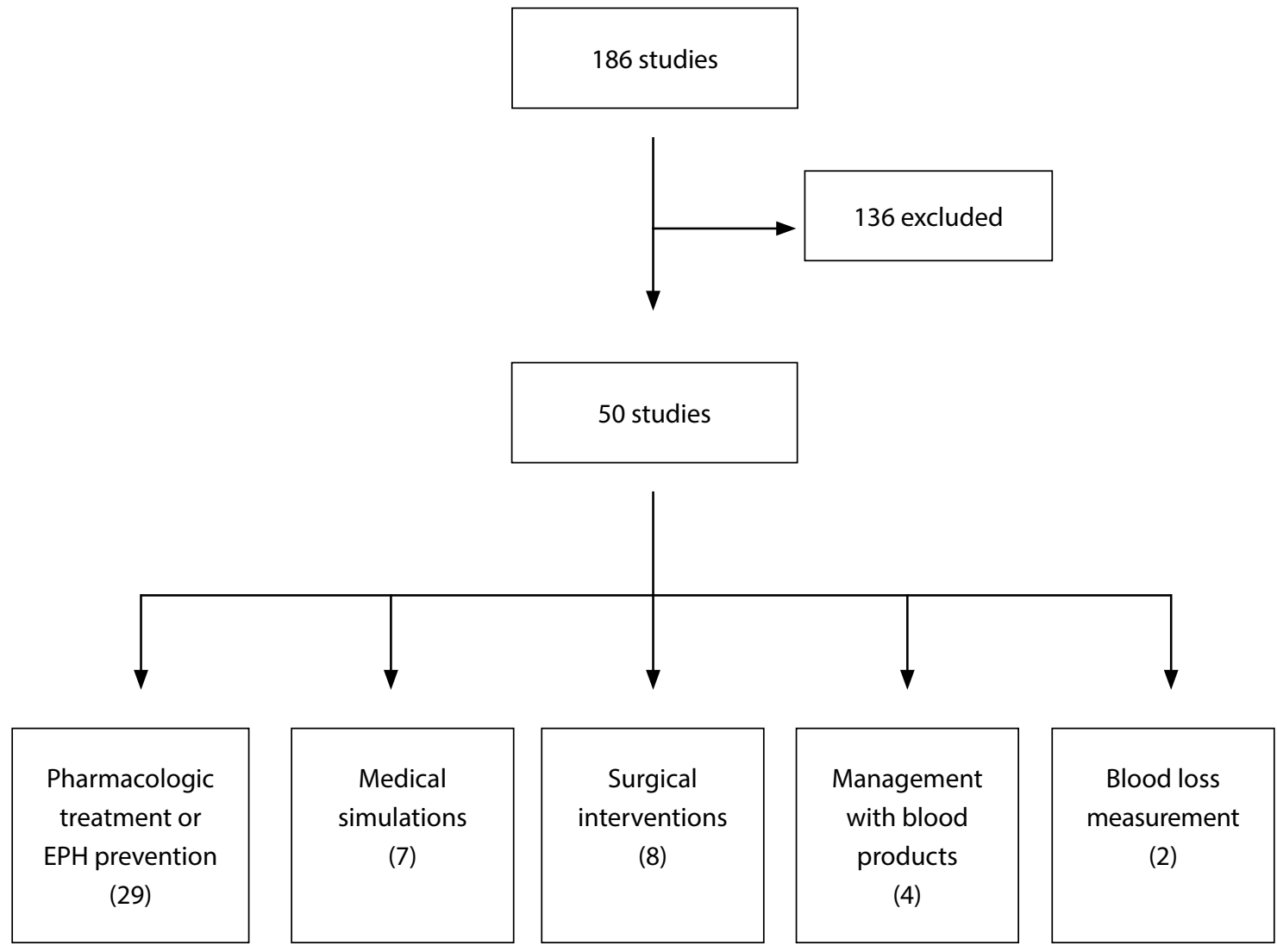

Figure 1. Study flow diagram 


\begin{tabular}{|c|c|c|c|}
\hline Country & Years & Population & PPH frequency \\
\hline Israel & 1988-2002 & 154311 & $0.4 \%$ \\
\hline $\begin{array}{l}\text { Africa } \\
\text { Asia } \\
\text { Europe }\end{array}$ & 2008 & 505379 & $\begin{array}{l}\text { Severe EPH: } \\
\mathbf{0 . 3 - 3 . 8 \%} \\
\mathbf{2 . 7 \%} \\
\mathbf{5 . 5 \%}\end{array}$ \\
\hline $\begin{array}{l}\text { Asia, Africa, } \\
\text { Middle East, } \\
\text { Latin America } \\
\text { (data from } \\
28 \text { countries) }\end{array}$ & 2010-2011 & 274985 & VD: $1.2 \%$ \\
\hline WHO & 2012 & & $2 \%$ \\
\hline USA & 1995-2004 & 870000 & $2.93 \%$ \\
\hline USA & 1999-2008 & 8500000 & $3 \%$ \\
\hline USA & 2006-2012 & 1339397 & CS: $2 \%$ \\
\hline Canada & 2003-2010 & 2200000 & $6.2 \%$ \\
\hline Norway & 1999-2004 & 307415 & Severe EPH: 1.1\% \\
\hline Norway & 2008-2011 & 43105 & Severe EPH: $\mathbf{2 . 5} \%$ \\
\hline United Kingdom & 2003-2013 & 24230 & CS: $12.4 \%$ \\
\hline France & 2004-2006 & 146781 & $6.4 \%$ \\
\hline France & 2016 & 3917 & $\begin{array}{l}\text { VD UPPBL: } \mathbf{1 1 \%} \\
\text { VD EPH: } \mathbf{1 1 . 2 \%}\end{array}$ \\
\hline Nederland & 2000-2008 & 1599867 & $4.5 \%$ \\
\hline Denmark & 2008 & 147132 & $\begin{array}{l}\text { CS: } \mathbf{2 . 2 4} \% \\
\text { VD: } 1.75 \%\end{array}$ \\
\hline Ireland & 1999-2009 & 649019 & $2.6 \%$ \\
\hline Spain & 2017 & 1352691 & $3 \%$ \\
\hline Brazil & 2010 & 9555 & $12.5 \%$ \\
\hline RPA & 2012 & 15725 & $2.5 \%$ \\
\hline Nigeria & 2014 & 4889 & $3.4 \%$ \\
\hline India & 2010-2012 & 96 & $\begin{array}{l}\text { CS: } 1.8 \% \\
\text { VD: } 1.3 \% \\
\text { Instrumental: } 5.3 \%\end{array}$ \\
\hline Tunisia & 2010-2013 & 39 & $\begin{array}{l}\text { Severe PPH } \\
\text { included } \\
\text { to the study }\end{array}$ \\
\hline Japan & 2011 & 1294 & VD: $\mathbf{3 3 \%}$ \\
\hline German & 2010-2013 & 1550 & $8.4 \%$ \\
\hline
\end{tabular}

fetus ( $>4000 \mathrm{~g})(\mathrm{OR}=1.7-1.9)$. Uterine abnormalities such as uterine fibroids (OR $=2.0-2.7$ ) also played an important role in the incidence of EPH [6]. Pregnancy complications, such as maternal anemia (hemoglobin level below $9[\mathrm{~g} / \mathrm{dL}]$ ) $(\mathrm{OR}=4.1)$, hypertensive disorders (OR $=1.6-3.6)$, gestational diabetes mellitus ( $O R=1.6)$, a multiple gestation $(\mathrm{OR}=1.5-3.7)$, polyhydramnios $(\mathrm{OR}=2.6)$ and preterm delivery $(O R=2.6)$ were significantly correlated with $E P H$ [12].

Maternalfever $(\mathrm{OR}=1.7-2.5)$, laborinduction $(\mathrm{OR}=1.5-1.7)$ and instrumental ( $O R=1.2-2.9)$ or operative delivery $(\mathrm{OR}=1.4-5.7)$ increase the risk of EPH. Retained placenta increase the risk of hemorrhage immediately after delivery $(\mathrm{OR}=3.5-4.1)$ as well as after subsequent pregnancy [12].

Sociodemographic factors, such as obesity [BMI > $\left.35\left(\mathrm{~kg} / \mathrm{m}^{2}\right)\right](\mathrm{OR}=2.3)$, mother's age over 35 years $(\mathrm{OR}=1.5-1.7)$ and Middle Eastern ethnicity $(\mathrm{OR}=1.8)$ increase the risk of EPH [13]. Conversely, smoking $(\mathrm{OR}=0.8)$ during pregnancy seems to reduce the risk of $\operatorname{EPH}[6,13]$. All the mentioned risk factors of PPH are shown in Table $2[6,10,14]$.

Risk factors of UPPBL are similar to those in EPH and include Asian ethnicity $(\mathrm{aOR}=2.3)$, previous cesarean section $(\mathrm{aOR}=3.4)$, episiotomy $(\mathrm{aOR}=2.6)$, primiparity, prolonged labor, instrumental delivery and retained placenta [6].

\section{Prevention}

WHO guidelines for the prevention of EPH include a thorough assessment of possible risk factors as the primary prophylaxis of this complication. Moreover, pharmacological prophylaxis includes $10 \mathrm{IU}$ of oxytocin in bolus (intravenously or intramuscularly), $100 \mu \mathrm{g}$ of carbetocin (intravenously or intramuscularly), misoprostol (400 $\mu \mathrm{g}$ or $600 \mu \mathrm{g}$, per os), ergometrine/methylergometrine (200 $\mu \mathrm{g}$, intramuscularly or intravenously) or oxytocin and ergometrine together (5 IU and $500 \mu \mathrm{g}$, intramuscularly) [15]. According to German guidelines 3-5 IU of intravenous oxytocin or $100 \mu \mathrm{g}$ of intravenous carbetocin should be recommended (Tab. 3.) [1]. Conversely, RCOG suggested $0.5-1 \mathrm{~g}$ of intravenous injection of tranexamic acid, carboprost or misoprostol to be superior to oxytocin prophylaxis. However oxytocin and/or ergometrine or $100 \mu \mathrm{g}$ of intravenous carbetocin is highly advised, similarly to the guidelines of the Society of Obstetricians and Gynaecologists of Canada [3]. RCOG guidelines suggest that the prevention of minor EPH with 5 IU and 10 IU of oxytocin has comparable results [3]. ACOG recommends to prevent EPH by using $10 \mathrm{IU}$ of oxytocin intramuscularly or intravenously as the most effective [4]. An intravenous bolus of tranexamic acid at a dose of $0.5-2 \mathrm{~g}$ (15-30 mg/kg BW) should also be considered $[2,3]$. Moreover, it could be used as prophylaxis of EPH afterVD.

In twin pregnancies carbetocin prophylaxis of EPH after CS seems to be more effective than oxytocin in the prevention of EPH [16]. The authors found several publications concerning a higher efficacy of carbetocin than oxytocin in the $3^{\text {rd }}$ stage of labor. Moreover, in another study carbetocin was a better alternative to traditional oxytocin in the prevention of PPH after vaginal delivery. The most significant adverse effect after drug administration was hypotension with no difference between those two drugs. Pruritus was the only symptom which was more often experienced in carbetocin-treated group. By contrast, the authors of another study reported that carbetocin had the same effectiveness as oxytocin at lower doses and needed less time to be effective. Conversely, misoprostol needed the longest period to reach sufficient uterine contractility [17]. No differences in effectiveness were 
Table 2. Risk factors of PPH $[10,15,17,21,22,25,27,30,36,41-44]$ the incidence of severe postpartum hemorrhage (PPH

\begin{tabular}{|c|c|c|}
\hline \multirow{2}{*}{$\begin{array}{l}\text { Risk factors of PPH } \\
\text { Mother diseases and pregnancy- } \\
\text { associated conditions }\end{array}$} & \multirow[b]{2}{*}{ OR } & \multirow[b]{2}{*}{$95 \% \mathrm{Cl}$} \\
\hline & & \\
\hline Past history of PPH & $2.3-10.5$ & $1.3-10.6$ \\
\hline Uterine anomaly in the past & 2.4 & $1.2-5.0$ \\
\hline Uterine surgery in the past & 3.4 & $1.6-7.1$ \\
\hline Multiple pregnancy & $1.5-3.7$ & $1.3-5.3$ \\
\hline IVF/ICSI & $1.8-2.9$ & $2.2-3.9$ \\
\hline Preeclampsia or HELLP syndrome & $1.8-3.6$ & $1.6-5.7$ \\
\hline Hypertension disorder & $1.6-2.0$ & $1.1-3.9$ \\
\hline Chorioamnionitis & 2.9 & $2.5-3.4$ \\
\hline Delivery $<37$ weeks of gestation & 2.6 & $2.3-3.0$ \\
\hline Delivery $>41$ weeks of gestation & $1.6-1.9$ & $1.0-2.8$ \\
\hline Fibroids & $2.0-2.7$ & $1.8-4.2$ \\
\hline Lacerations & 2.4 & $2.0-2.8$ \\
\hline Nulliparity & $1.1-2.0$ & $1.0-2.6$ \\
\hline Third pregnancy & 1.3 & $1.1-1.6$ \\
\hline Anemia $(\mathrm{Hb} \leq 9.0 \mathrm{~g} / \mathrm{dL})$ & 4.1 & $2.8-6.1$ \\
\hline GDM & 1.6 & $1.1-2.3$ \\
\hline Polyhydramnios & 2.6 & $1.2-5.5$ \\
\hline Anticoagulant medication & 4.7 & $2.8-7.7$ \\
\hline Placenta previa & $3.0-7.0$ & $2.9-7.3$ \\
\hline \multicolumn{3}{|l|}{ Labour related factors } \\
\hline Retained placenta & $3.5-4.1$ & $2.1-5.8$ \\
\hline Placenta accrete & 3.3 & $1.7-6.4$ \\
\hline Instrumental delivery & $1.2-2.9$ & $0.9-3.5$ \\
\hline CS & $1.4-5.7$ & $1.2-6.5$ \\
\hline CS in the second stage of labor & $2.1-3.4$ & $1.2-4.7$ \\
\hline Uterine rupture & 11.6 & $9.7-13.8$ \\
\hline Labour Induction & $1.5-1.7$ & $1.1-2.0$ \\
\hline PROM & $1.4-1.5$ & $1.0-1.9$ \\
\hline Body temperature in labour $>38^{\circ} \mathrm{C}$ & $1.7-2.5$ & $1.1-3.6$ \\
\hline Labour induction or augmentation & $1.4-2.0$ & $1.1-2.4$ \\
\hline LGA & $1.7-1.9$ & $1.2-2.6$ \\
\hline \multicolumn{3}{|l|}{ Sociodemographic } \\
\hline $\mathrm{BMI}>35 \mathrm{~kg} / \mathrm{m}^{2}$ & 2.3 & $1.3-3.6$ \\
\hline Age $>35$ years & $1.5-5.7$ & $1.1-7.1$ \\
\hline Middle Eastern descent & 1.8 & $1.2-2.7$ \\
\hline African descent & 1.5 & $1.1-2.2$ \\
\hline Smoking & 0.8 & $0.6-1.0$ \\
\hline
\end{tabular}

reported for an intravenous administration of $100 \mu \mathrm{g}$ of carbetocin and $5 \mathrm{IU}$ of oxytocin [18]. Furthermore, no differences in efficacy were found between $10 \mathrm{IU}$ and $30 \mathrm{IU}$ of oxytocin administered intravenously, but the higher dose was effective for a longer period (8-12 vs 2-4 hours) [19].

\section{Table 3. Carbetocin usage}

Multiple pregnancy

$\geq 4$ deliveries in past

$\geq 2$ cesarean sections in past

Other uterine scare

Large uterine fibroids

PPH or uterine atony in the past

Suspected fetal macrosomia

Polyhydroamnios

Placenta previa

Placenta accreta

$\mathrm{BMI}>35 \mathrm{~kg} / \mathrm{m}^{2}$

$\mathrm{HCT}<35 \%$

Fibrinogen concentration $<4 \mathrm{~g} / \mathrm{L}$

$\mathrm{PLT}<100000$

$\mathrm{BMI}$ - body mass index; HCT - hematocrit; PLT - platelets

The authors found the advantages of 5 IU of oxytocin administered intramuscularly over $200 \mu \mathrm{g}$ of sublingual misoprostol. However, misoprostol is more cost-effective, may be stored at room temperature and is easier to use. Therefore, it may be a good alternative to oxytocin. Heatstable carbetocin compared to oxytocin and $800 \mu \mathrm{g}$ of rectal misoprostol had a similar effectiveness compared to $10 \mathrm{IU}$ of intramuscular oxytocin in the $3^{\text {rd }}$ stage of labor [20].

Several studies compared the effectiveness of $10 \mathrm{IU}$ of bolus of oxytocin with $600 \mu \mathrm{g}$ of intramuscular misoprostol in the prevention of EPH, with no significant differences between groups. Furthermore, other authors found that $800 \mu \mathrm{g}$ of misoprostol seemed to be more effective than the standard dose of oxytocin [21].

A combination of methylergonovine and oxytocin infusion during CS successfully decreased severity of EPH [22]. On the other hand a combination of misoprostol and oxytocin seemed to increase the risk of side effects related to pharmacotherapy, such as fever, nausea and shivering.

Tranexamic acid was effective in reducing the rate of $\mathrm{EPH}$, especially if administered within 3 hours after labor (RR 0.69, 95\% Cl: 0.5-0.9; $\mathrm{p}=0.008$ ) [23]. Another study demonstrated that tranexamic acid did not enhance the anti-hemorrhagic effect in a group of women after oxytocin administration [24]. The supplementation of fibrinogen after $\mathrm{EPH}$ in women with normal fibrinogen level also did not improve those results. In contrast to those findings some researchers recommended a routine administration of $3 \mathrm{~g}$ of fibrinogen in case of EPH.

Delayed umbilical cord clamping and cord drainage presented a protective effect against EPH. 


\section{Treatment}

It is important to estimate the occurrence of probable reversible reasons for EPH. An injury of the uterus or the genital tract seems to be the most recognizable factor and requires primary surgical treatment.

The management of retained placenta includes controlled cord traction, Credé maneuver and manual placenta removal [2].

External uterine massage or bimanual uterine compression should be considered as the first-line treatment of uterine atony. The second-line treatment might involve intrauterine tamponade with Foley catheter, or other dedicated intrauterine balloon catheters, which effectiveness reached up to $80-90 \%$ [25]. The availability, easy usage and safety are important issues of this method when uterine subatony or undiagnosed focal placenta accreta is present. However, no papers have been found to compare those methods. Early balloon tamponade is effective when used before coagulopathy occurrence.

Another tools utilized in the treatment of uterine subatony are uterine compression sutures (B-Lynch, Cho and Hayman) with effectiveness estimated to $60-75 \%$ [26]. However there is insufficient data concerning comparison of different techniques. On the other hand endovascular balloon techniques seem to be more effective (uterine preservation, less blood loss and higher postoperative hemoglobin levels). Several previous studies showed similar effectiveness of compression sutures, intrauterine tamponade and uterine artery ligation. However, intrauterine tamponade should be preferred option because of lower costs and invasiveness as well as faster therapeutic effect. In severe cases combination of aforementioned methods should be considered to preserve female fertility [26].

Obviously, pharmacologic treatment should be introduced simultaneously - intravenous 10-30 IU of oxytocin or $100 \mu \mathrm{g}$ of intravenous bolus of carbetocin, with similar clinical effectiveness (blood loss, severe postpartum hemorrhage, blood products transfusions). On the other hand few studies has shown higher effectiveness (amount of blood loss and the need for other uterotonics) of $100 \mu \mathrm{g}$ carbetocin vs 5 IU oxytocin in EPH management [17].

Other vasoconstrictors, such as methylergometrine 0.2-0.4 mg intramuscularly, PGF2a (enzaprost) $1 \mathrm{mg}$ into the uterine muscle, PGE1 (misoprostol) 600-1000 $\mu \mathrm{g}$ per rectum are also used [2].

Total hysterectomy is the last-ditch intervention in case of uterine atony. The incidence of such intervention constitutes $1.1-2.3 \%$ of EPH [27] and 0.63 per 1000 childbirths. Over 30 minutes desmopressin infusion $0.3 \mu \mathrm{g} / \mathrm{kg}$ BW should be considered in women with hypovolemic shock [28].
The administration of crystalloids and colloids should be obligatory apart from drugs increasing the contractility of the uterus. In case of massive perinatal bleeding, blood product transfusion (4 or more units of packed red blood cells (RBC), fresh frozen plasma (12-15 mL/kg BW), (25 IU/kg BW) prothrombin complex concentrate and platelets, when platelet count is below $75^{*} 10^{9} / \mathrm{l}$ ) should be considered $[2,3]$. One study suggested cell salvage but this procedure is very expensive and not easily available.

$1 \mathrm{~g}$ of calcium chlorate and the substitution of fibrinogen (30-60 mg/kg BW), rFVIla ( $90 \mu \mathrm{g} / \mathrm{kg}$ BW or $15-20 \mathrm{IU} / \mathrm{kg} \mathrm{BW}$ ) or factor XIII should be considered when severe bleeding is present [3].

Late EPH requires vaginal microbiology and subsequent antimicrobial treatment of endometritis if such a diagnosis is confirmed. Ultrasound should be performed to look for placenta retained tissue and subsequent surgical intervention should be planned.

Medical simulations of EPH are important for the improvement of medical staffskills. A reduction in the number of possible errors, easier and faster medical interventions, shortening the time to the preparation of blood products, more appropriate blood loss evaluation, self-confidence and comfort level, practices in surgical and pharmacological management are the main goals of medical simulations [29]. Such courses improve the recognition of EPH and shorten the duration of appropriate medical intervention - uterine massage and the administration of second-line medications. The results showed an improvement of medical skills in that publication from $27.3 \%$ to $63.6 \%(p=0.01)$ [30]. Another study showed a significant improvement in team cooperation [31]. Some research also showed that such simulations have a positive influence on obstetric outcomes in the future. A subsequent trial showed a higher rate of appropriate EPH evaluation and fundal massage implementation. Another publication proved that one-day simulation caused a significant improvement in medical skills and the effect persisted over the next 3 months $(0.4 \%$ vs $0.03 \%$, OR $19,95 \% \mathrm{Cl} 2.5-147$ ) [32].

\section{DISCUSSION}

An inconsisenst definition of EPH, varying across countries contributes to the publication of non-comparable results and different conclusions concerning $\mathrm{EPH}$. The frequency of EPH was compared in this study and an increasing trend was observed. Furthermore, EPH is the main cause of maternal mortality [32]. Apart from death it is associated with severe maternal condition after childbirth. Therefore, an interest in the subject is not surprising. Risk factors listed in the Results section are one of research areas. Prediction strategy assumes risk factor evaluation before any childbirth. EPH causes may be easier to memorize by remembering 
their division in 4Ts: tone, tissue, trauma and thrombin with higher attention to uterine atony as the most frequent cause of EPH [10]. It seems that an increased rate of EPH is caused by an increased level of uterine atony secondary to a higher rate of CSs. Regrettably, EPH occurs in two-thirds of women without any risk factors [28].

It is commonly known that it is better to prevent than to treat possible complications. For that reason, the main attention is paid to preventive methods which consist of uterotonics (oxytocin, carbetocin, enzaprost/carboprost or misoprostol, ergometrine or methylergometrine) and tranexamic acid. Thus, the prophylaxis should include 3-10 IU of oxytocin intravenously or $100 \mu \mathrm{g}$ of carbetocin intravenously in the $3^{\text {rd }}$ stage of labor and $100 \mu \mathrm{g}$ of carbetocin intravenously during CS in high risk patients. Economic issues should also be considered because of a higher carbetocin cost. Moreover, an intravenous administration of oxytocin was shown as more effective (due to severe EPH, blood transfusion and admission to a high dependency unit) than intramuscular administration in the $3^{\text {rd }}$ stage of labor [33]. Another trial showed acceptable outcomes of misoprostol in comparison with oxytocin, but a high price of misoprostol was emphasized [34]. Previous studies showed also the efficacy of other uterotonics in the absence of oxytocin and carbetocin. Tranexamic acid should be also considered.

Apart from early prophylaxis, in any case of EPH pharmalological and if severe - surgical treatment should be introduced. Pharmacologic intervention seems to be superior to a surgical one. However, if surgical intervention is necessary, no delay in its performance should occur, especially when regards pelvic vessel occlusion, compression sutures (eg B-Lynch) management or emergency hysterectomy. Hamilton maneuver is the best option in preparation to the surgical procedures.

In case of hypovolemic shock, desmopressin $0.3 \mu \mathrm{g} / \mathrm{kg}$ of BW and other vasoconstrictors like norepinephrine should be considered.

Pelvic packing may be performed in case of the lack of selective arterial embolization, for patient transport to a tertiary care unit or in case of persistent bleeding after hysterectomy [7].

Intravenous infusions of crystalloids and colloids should be obligatory apart from previously mentioned drugs. Moreover, blood transfusion may be necessary $[2,3]$. Fibrinogen substitution (30-60 mg/kg BW), which could reach $\geq 2 \mathrm{~g} / \mathrm{L}$ as well as rFVIla $(90 \mu \mathrm{g} / \mathrm{kg}$ BW or 15-20 IU/kg BW) or factor XIII use could improve the PPH outcomes [3].

Medical simulations of EPH are important for the improvement of medical staff skills, which had an influence on EPH outcomes. Importantly, attention should be paid to becoming familiar with hospital protocols, team work improvement, understanding one's own mistakes, building self-confidence, and reduced perception of stress. Blood loss evaluation is also improved after such trainings. It seems rational that it should be implemented as early as the beginning of medical practice and repeated every 3 months.

No research on the frequency of EPH in the Polish population is currently available. Further studies should also evaluate more accurate blood loss measurement methods and their customization.

\section{REFERENCES}

1. Schlembach $\mathrm{D}$, Helmer $\mathrm{H}$, Henrich $\mathrm{W}$, et al. Peripartum Haemorrhage, Diagnosis and Therapy. Guideline of the DGGG, OEGGG and SGGG (S2k Level, AWMF Registry No. 015/063, March 2016). Geburtshilfe und Frauenheilkunde. 2018; 78(04): 382-399, doi: 10.1055/a-0582-0122.

2. World Health Organization (WHO). SpringerReference., doi: 10.1007/springerreference_70205.

3. Prevention and Management of Postpartum Haemorrhage: Green-top Guideline No. 52. BJOG. 2017; 124(5): e106-e149, doi: 10.1111/14710528.14178, indexed in Pubmed: 27981719.

4. Practice Bulletin No. 183. Obstetrics \& Gynecology. 2017; 130(4): e168-e186, doi: 10.1097/aog.0000000000002351.

5. Diaz V, Abalos E, Carroli G. Methods for blood loss estimation after vaginal birth. Cochrane Database Syst Rev. 2018; 9: CD010980, doi: 10.1002/14651858.CD010980.pub2, indexed in Pubmed: 30211952.

6. Girault A, Deneux-Tharaux C, Sentilhes L, et al. Undiagnosed abnormal postpartum blood loss: Incidence and risk factors. PLoS One. 2018; 13(1): e0190845, doi: 10.1371/journal.pone.0190845, indexed in Pubmed: 29320553.

7. Touhami O, Marzouk SB, Kehila M, et al. Efficacy and safety of pelvic packing after emergency peripartum hysterectomy $(E P H)$ in postpartum hemorrhage (PPH) setting. Eur J Obstet Gynecol Reprod Biol. 2016; 202: 32-35, doi: 10.1016/j.ejogrb.2016.04.013, indexed in Pubmed: 27156153.

8. Bloch EM, Ingram C, Hull J, et al. South Africa Program of the NHLBI Recipient Epidemiology and Donor Evaluation Study-III (REDS-III). Risk factors for peripartum blood transfusion in South Africa: a case-control study. Transfusion. 2018; 58(9): 2149-2156, doi: 10.1111/trf.14772, indexed in Pubmed: 29989178.

9. Dunkerton $\mathrm{SE}$, Jeve $\mathrm{YB}$, Walkinshaw N, et al. Predicting Postpartum Hemorrhage (PPH) during Cesarean Delivery Using the Leicester PPH Predict Tool: A Retrospective Cohort Study. Am J Perinatol. 2018; 35(2): 163-169, doi: 10.1055/s-0037-1606332, indexed in Pubmed: 28847038.

10. Nyfløt LT, Sandven I, Stray-Pedersen B, et al. Risk factors for severe postpartum hemorrhage: a case-control study. BMC Pregnancy Childbirth. 2017; 17(1): 17, doi: 10.1186/s12884-016-1217-0, indexed in Pubmed: 28068990.

11. Ford JB, Patterson JA, Seeho SKM, et al. Trends and outcomes of postpartum haemorrhage, 2003-2011. BMC Pregnancy Childbirth. 2015; 15:334, doi: 10.1186/s12884-015-0788-5, indexed in Pubmed: 26670767.

12. Nyfløt LT, Stray-Pedersen B, Forsén L, et al. Duration of labor and the risk of severe postpartum hemorrhage: A case-control study. PLoS One. 2017; 12(4): e0175306, doi: 10.1371/journal.pone.0175306, indexed in Pubmed: 28384337

13. Horie S, Nomura K, Nakagawa J, et al. Factors Associated with Blood Loss after Delivery in 1,294 Mothers with Full-Term Singleton Baby. Nihon Eiseigaku Zasshi. 2016; 71(3): 208-215, doi: 10.1265/jjh.71.208, indexed in Pubmed: 27725424.

14. Miller CM, Cohn S, Akdagli S, et al. Postpartum hemorrhage following vaginal delivery: risk factors and maternal outcomes. J Perinatol. 2017; 37(3): 243-248, doi: 10.1038/jp.2016.225, indexed in Pubmed: 27977018.

15. World Health Organization (WHO). SpringerReference, , doi: 10.1007/springerreference_70205.

16. Sotillo L, Calle MD, Magdaleno F, et al. Efficacy of carbetocin for preventing postpartum bleeding after cesarean section in twin pregnancy. The Journal of Maternal-Fetal \& Neonatal Medicine. 2018: 1-5, doi: 10.1080/14767058.2018.1489532.

17. Maher MA, Sayyed TM, Elkhouly NI. Different routes and forms of uterotonics for treatment of retained placenta: a randomized clinical trial. J Matern Fetal Neonatal Med. 2017; 30(18): 2179-2184, doi: 10.1080/14767058.2016.1242124, indexed in Pubmed: 27677547. 
18. Mohamed Maged A, Ragab AS, Elnassery N, et al. Carbetocin versus syntometrine for prevention of postpartum hemorrhage after cesarean section. J Matern Fetal Neonatal Med. 2017; 30(8): 962-966, doi: 10.1080/14767058.2016.1192601, indexed in Pubmed: 27268381.

19. Cecilia M, Vijayaselvi R, Bansal $R$, et al. Ten units intravenous oxytocin over 2-4 $\mathrm{h}$ is as effective as 30 units over $8-12 \mathrm{~h}$ in preventing postpartum hemorrhage after cesarean section: A randomized controlled trial. Indian J Pharmacol. 2018; 50(5): 279, doi: 10.4103/ijp.IJP_419_18, indexed in Pubmed: 30636832.

20. Widmer M, Piaggio G, Nguyen T, et al. Heat-Stable Carbetocin Versus Oxytocin to Prevent Hemorrhage After Vaginal Birth. Obstetrical \& Gynecological Survey. 2018; 73(11): 613-614, doi: 10.1097/ogx.0000000000000616.

21. Chaudhuri P, Mandi S, Mazumdar A, et al. Rectally administrated misoprostol as an alternative to intravenous oxytocin infusion for preventing postpartum hemorrhage after cesarean delivery. J Obstet Gynaecol Res. 2014; 40(9): 2023-2030, doi: 10.1111/jog.12464, indexed in Pubmed: 25181622.

22. Sentürk Ş, Kağıtçı M, Balık G, et al. The Effect of the Combined Use of Methylergonovine and Oxytocin during Caesarean Section in the Prevention of Post-partum Haemorrhage. Basic Clin Pharmacol Toxicol. 2016; 118(5): 338-343, doi: 10.1111/bcpt.12500, indexed in Pubmed: 26449959.

23. Shakur H, Roberts I, Fawole B, et al. Effect of early tranexamic acid administration on mortality, hysterectomy, and other morbidities in women with post-partum haemorrhage (WOMAN): an international, randomised, double-blind, placebo-controlled trial. The Lancet. 2017; 389(10084): 2105-2116, doi: 10.1016/s0140-6736(17)30638-4.

24. Sentilhes L, Winer N, Azria E, et al. Tranexamic Acid for the Prevention of Blood Loss After Vaginal Delivery. Obstetrical \& Gynecological Survey. 2019; 74(1): 10-11, doi: 10.1097/ogx.0000000000000637.

25. Aderoba AK, Olagbuji BN, Akintan AL, et al. Condom-catheter tamponade for the treatment of postpartum haemorrhage and factors associated with success: a prospective observational study. BJOG. 2017; 124(11): 1764-1771, doi: 10.1111/1471-0528.14361, indexed in Pubmed: 27726298.

26. Practice Bulletin No. 183. Obstetrics \& Gynecology. 2017; 130(4): e168-e186, doi: 10.1097/aog.0000000000002351.
27. Marshall AL, Durani U, Bartley A, et al. The impact of postpartum hemorrhage on hospital length of stay and inpatient mortality: a National Inpatient Sample-based analysis. Am J Obstet Gynecol. 2017; 217(3): 344.e1-344.e6, doi: 10.1016/j.ajog.2017.05.004, indexed in Pubmed: 28502758.

28. Lier $\mathrm{H}$, von Heymann $\mathrm{C}$, Korte $\mathrm{W}$, et al. Peripartum Haemorrhage: Haemostatic Aspects of the New German PPH Guideline. Transfus Med Hemother. 2018; 45(2): 127-135, doi: 10.1159/000478106, indexed in Pubmed: 29765296.

29. Burns E, Hunter L, Rodd Z, et al. Developing and evaluating an online learning tool to improve midwives' accuracy of visual estimation of blood loss during waterbirth: An experimental study. Midwifery. 2019; 68: 65-73, doi: 10.1016/j.midw.2018.10.004, indexed in Pubmed: 30368119.

30. Marshall NE, Vanderhoeven J, Eden KB, et al. Impact of simulation and team training on postpartum hemorrhage management in nonacademic centers. J Matern Fetal Neonatal Med. 2015; 28(5): 495-499, doi: 10.3109/14767058.2014.923393, indexed in Pubmed: 24824110.

31. Letchworth PM, Duffy SP, Phillips D. Improving non-technical skills (teamwork) in post-partum haemorrhage: A grouped randomised trial. Eur J Obstet Gynecol Reprod Biol. 2017; 217: 154-160, doi: 10.1016/j. ejogrb.2017.08.030, indexed in Pubmed: 28898688.

32. van de Ven J, Fransen AF, Schuit E, et al. Does the effect of one-day simulation team training in obstetric emergencies decline within one year? A post-hoc analysis of a multicentre cluster randomised controlled trial. Eur J Obstet Gynecol Reprod Biol. 2017; 216: 79-84, doi: 10.1016/j. ejogrb.2017.07.020, indexed in Pubmed: 28738295.

33. Charles D, Anger H, Dabash R, et al. Intramuscular injection, intravenous infusion, and intravenous bolus of oxytocin in the third stage of labor for prevention of postpartum hemorrhage: a three-arm randomized control trial. BMC Pregnancy Childbirth. 2019; 19(1): 38, doi: 10.1186/s12884019-2181-2, indexed in Pubmed: 30658605.

34. Sørensen JL, van der Vleuten C, Rosthøj S, et al. Simulation-based multiprofessional obstetric anaesthesia training conducted in situ versus off-site leads to similar individual and team outcomes: a randomised educational trial. BMJ Open. 2015; 5(10): e008344, doi: 10.1136/bmjopen-2015-008344, indexed in Pubmed: 26443654. 